\title{
Increased early offspring growth can offset the costs of long-distance spawning migration in fish
}

\author{
Leonie Färber*, Joël M. Durant, Yngvild Vindenes, Øystein Langangen \\ Centre for Ecological and Evolutionary Synthesis (CEES), Department of Biosciences, University of Oslo, \\ PO Box 1066 Blindern, 0316 Oslo, Norway
}

\begin{abstract}
For long-distance migrations to pay off for individual fish, the energetic costs must be counterbalanced by benefits. Understanding the fitness trade-offs associated with migration is essential for our ability to sustainably manage migratory species. Here, we investigated such trade-offs associated with the spawning migration of Northeast Arctic cod Gadus morhua, a stock of high historical and commercial value known to be able to migrate more than $1000 \mathrm{~km}$ southward to reach suitable spawning grounds. Reaching the more distant spawning grounds requires more energy and hence leaves less energy available for processes such as egg production. Previous studies have indicated that increased larval survival (e.g. from rapid early development in warmer southern waters) may offset the parental costs of migration. However, it was suggested that spatial variability in survival of early life stages might cancel out this survival benefit. As an alternative, we ask if the fitness benefit of long-distance migration may reside in increased offspring growth. Using an integral projection model incorporating effects of body length and migration distance, we quantified the increase in offspring growth needed to offset parental costs of long-distance migration on fitness. Our results suggest that a $12.5 \%$ length increase of juvenile cod is required to offset parental costs of long-distance migration. This is within the estimated growth benefit of $20 \%$ suggested by drift models of early life stages of cod. These results highlight the potential importance of offspring growth as another factor explaining the benefit of longdistance migration, broadening our knowledge on spawning migration.
\end{abstract}

KEY WORDS: Spawning migration - Northeast Arctic cod - Offspring growth - Cost $\cdot$ Benefit · Trade-off $\cdot$ Integral projection model

\section{INTRODUCTION}

Migratory behaviour occurs in various organisms, including insects, birds, fish, and mammals. This behaviour can increase fitness through higher survival and reproductive success (Rankin \& Burchsted 1992, Alerstam et al. 2003, Dingle 2014); however, migration also has costs, for instance in energy use, leading to important trade-offs in the life histories of species balancing different migratory or more stationary strategies (Dingle 2014).

The spawning migration of fish often involves a parent-offspring trade-off, or as Trivers (1974) called it, a parent-offspring conflict. However, depending

${ }^{*}$ Corresponding author: l.a.farber@ibv.uio.no on the species, the combination of traits affected by the trade-off(s) may differ. For example, the parental cost of migration may include energy costs associated with movement or missed feeding opportunities, which may both lead to reduced growth potential and decreases in fecundity and survival through augmented susceptibility to disease or predation (including fishing; Rankin \& Burchsted 1992, Sutherland 1996, Jørgensen et al. 2006, 2008). Potential offspring benefits include increased feeding opportunities, reduced predation pressure, and better environmental conditions such as favourable temperature and currents, which are typically associated with increased survival and growth of the offspring (Dodson 1997,

() The authors 2018. Open Access under Creative Commons by Attribution Licence. Use, distribution and reproduction are unrestricted. Authors and original publication must be credited. 
Slotte 1999, Jørgensen et al. 2008). Spawning migration is a common trait for many harvested fish species, from small pelagic fish like capelin Mallotus villosus (Rose 2005) or Atlantic herring Clupea harengus (Slotte 1999), to large predatory fish like Atlantic cod Gadus morhua (Harden Jones 1968) or Atlantic bluefin tuna Thunnus thynnus (Block et al. 2005). Moreover, the distance migrated can depend on the fish's body condition (for example, length and energy storage; Slotte 1999, Jørgensen et al. 2008) but also on climatic conditions (Sundby \& Nakken 2008). Thus, understanding which factors and fitness tradeoffs shape migration behaviour is essential for our understanding of the ecology of migration as well as for our ability to design useful conservation and management strategies in the light of a changing environment.

The Northeast Arctic (NEA) cod stock exhibits one of the most extensive and variable migrations among the cod stocks in the North Atlantic (Robichaud \& Rose 2004). The distance migrated from the feeding ground in the Barents Sea to the spawning grounds along the Norwegian coast can vary from a few 100s of $\mathrm{km}$ to spawning grounds in northern Norway, to more than $1000 \mathrm{~km}$ to grounds in southern Norway (see Fig. 1). For this stock, a potentially reduced number of offspring due to the energetic costs of long-distance migration is thought to be compensated by an increase in offspring survival in their first year of life before they become demersal (Jørgensen et al. 2008). This has been further corroborated by a simulation study, showing increased survival of the pelagic life stages with increased migration distance (Opdal et al. 2011). However, using drift models, Langangen et al. (2016) showed that when accounting for empirically estimated spatial variation in early offspring survival (eggs, larvae, and pelagic juveniles) of NEA cod, much of the offspring survival benefit of more distant spawning grounds disappeared. They suggested that the main benefit of the long-distance spawning migration in this stock may be an increase in the early offspring growth rate, where offspring spawned at central spawning grounds along the Norwegian coast are around $20 \%$ larger than offspring spawned at northern spawning grounds (Langangen et al. 2016). Indeed, at the southern spawning grounds, the growth rate of the offspring is higher due to warmer temperatures (Suthers \& Sundby 1993, Folkvord 2005, Opdal et al. 2011) and potentially also due to higher food availability (cf. Langangen et al. 2016).

In this study, we developed a demographic population model to test whether increased early offspring growth in NEA cod (i.e. growth in their first year of life) can offset the fitness costs of reduced egg numbers due to long-distance migration. This would suggest that the NEA cod spawning migration involves a quality-quantity trade-off in offspring, rather than (or in addition to) a parent-offspring trade-off. An increase in early offspring growth could also lead to long-term effects on the rest of the life history and population growth (Beckerman et al. 2002, Vindenes \& Langangen 2015), e.g. through increased survival and fecundity later in life.

Quantifying the fitness consequences of migration is challenging (cf. Jørgensen et al. 2006). Demographic models allow us to overcome this challenge by linking individual-level processes (e.g. survival, reproduction, and growth) accounting for effects of migration to population-level outcomes like mean fitness (e.g. the long-term population growth rate $\lambda_{\text {; }}$ Easterling et al. 2000, Caswell 2001). Fish population dynamics are regularly studied using matrix models, where the population is structured into discrete classes (typically age and/or life history stages; Fournier et al. 1998, Armsworth 2002, Durant et al. 2013, Durant \& Hjermann 2017). However, vital rates of fish are often better described as a function of size (length or weight) rather than age or stage. Effects of continuous-state variables like size can be incorporated by using an integral projection model (IPM; Easterling et al. 2000), the continuous-state analogue to matrix models (Caswell 2001). The asset of an IPM is that it provides a useful model framework to investigate how different underlying mechanisms determine fitness in continuous trait-structured populations (Ellner et al. 2016, Vindenes et al. 2016). Furthermore, they are of intermediate complexity, and hence rely on few parameters, yet are complex enough to capture the essential underlying mechanisms. Here, we developed and parameterized an IPM for NEA cod, accounting not only for length but also migration distance. We used the model to investigate potential fitness trade-offs (measured by $\lambda$ ) of spawning migration, and specifically to test whether benefits to offspring growth might realistically offset the fecundity costs of long-distance migration. We considered the hypothesis of increased offspring growth being one benefit of long-distance migration as being biologically plausible if the offspring size offset needed to compensate for the energy cost of parental migration is less than $20 \%$ between a more central spawning ground (Lofoten) and a northern spawning ground (Finnmark, see Fig. 1; Langangen et al. 2016). A much larger offspring size benefit might be biologically unreasonable, thus we would reject our hypothesis. 


\section{MATERIALS AND METHODS}

\section{NEA cod}

The NEA cod (also known as Arcto-Norwegian cod or Barents Sea cod) is currently one of the most productive cod stocks in the world (Yaragina et al. 2011). It has a high commercial value, especially for Norway and Russia but also for other countries (Yaragina et al. 2011). The NEA cod has its feeding grounds in the Barents Sea and several distinct spawning grounds along the Norwegian coast (Yaragina et al. 2011). The Atlantic and the Norwegian Coastal Current flow northwards into the Barents Sea (Ozhigin et al. 2011), thus the southwards migration of the fish to the spawning grounds is believed to be mainly upstream (ICES 1994). At the spawning grounds, pelagic eggs are released and develop into larvae and juveniles as they drift with the currents back into the Barents Sea (Yaragina et al. 2011).

\section{Constructing the IPM}

Here, we describe the main components of the model; see the Supplement at www.int-res.com/articles/ suppl/m600p141_supp.pdf for further details. The main state variable is length $(\mathrm{cm})$ of the female adult and offspring cod, and we included migration distance, $d(\mathrm{~km})$, as a parameter assumed not to vary over maternal length (see 'Discussion' for elaborations on this assumption).

The model is female-based but was parameterized using estimated average vital rates from both sexes. The projection kernel $K(y, x, d)$ is a function of the vital rates describing the average annual population growth contributions of individuals from length $x$ to length $y$, for all combinations of $x$ and $y$, depending on migration distance. The projection kernel can be decomposed into 2 components:

$K(y, x, d)=S(x) G(y ; x)+O(x, d) L_{1}(y, d)(1)$

The first term represents growth and survival of fish from age 1 onwards (offspring enter the model at age 1). It is the product of the survival probabil- ity function, $S(x)$, and the distribution of next year's length, $G(y ; x)$; these processes do not depend on migration distance in our model, as we assumed that the cost of migration only affects the number of eggs produced by a female. The second term is the product of the offspring function (number of age-1 offspring), $O(x, d)$, and the offspring length distribution at age $1, L_{1}(y, d)$, both depending on $d$. As a baseline migration distance in the model, defined to have $\lambda=1$, we chose the Lofoten spawning ground (Fig. 1), which is the main spawning ground for NEA cod (Sundby \& Nakken 2008) corresponding to an approximate distance of $d=780 \mathrm{~km}$ (Jørgensen \& Fiksen 2006).

The survival probability function, $S(x)$ (Fig. 2a), was calculated from instantaneous mortality estimates (Langangen et al. 2014, Ohlberger et al. 2014, Bogstad et al. 2016), which were converted to survival estimates and included fishing mortality from age 3 onwards (ICES 2015, Table S1 in the Supplement). The survival probability at $x=200 \mathrm{~cm}$ is set to $S(200)=0$ (Fig. 2a).

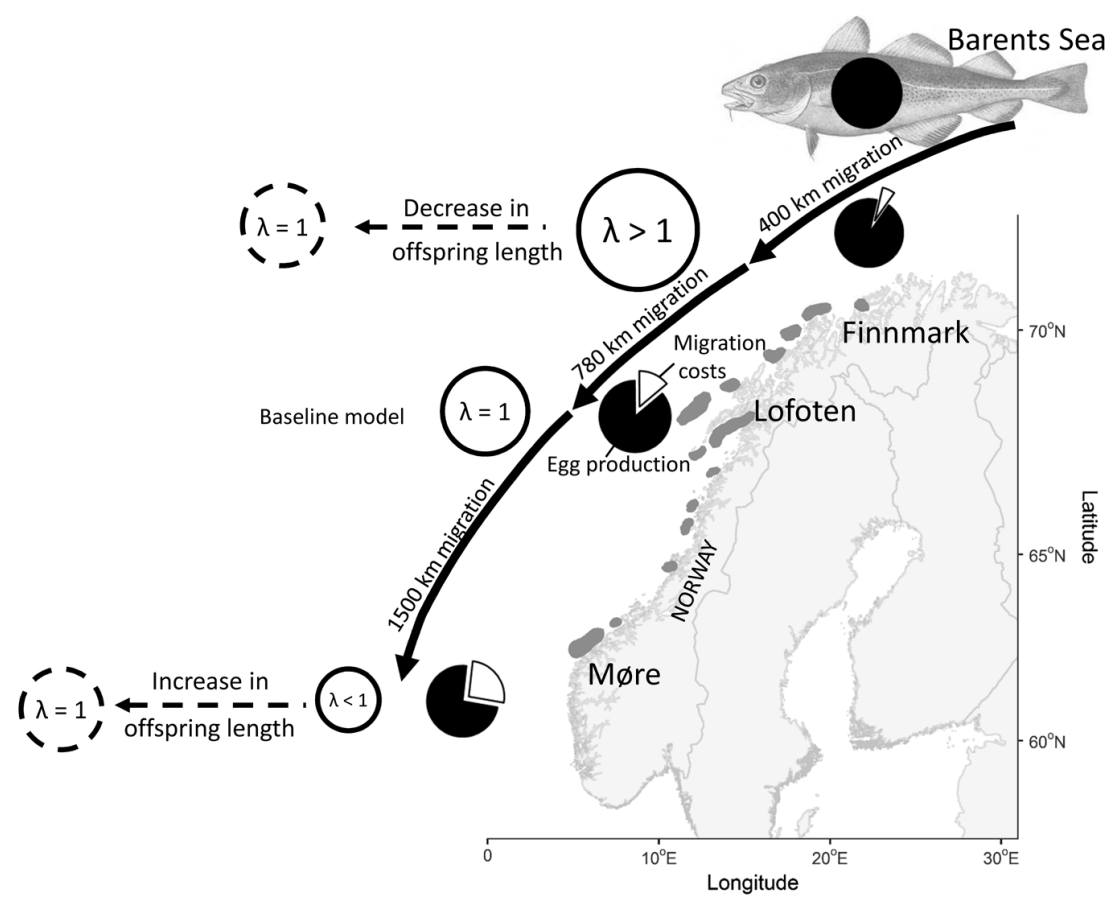

Fig. 1. Schematic overview of the model. The right side of the figure shows the spawning grounds of Northeast Arctic (NEA) cod (grey shaded area) along the Norwegian coast. Black slice in the pie charts: amount of energy available for reproduction (thus egg numbers) at the respective spawning grounds (maximum amount if spawning would occur in the Barents Sea; full black circle); white slices: migration costs (calculated for a $100 \mathrm{~cm}$ large female). With an increase in migration distance, $\lambda$ declines from $\lambda>1$ to $\lambda<1$ at the spawning grounds south of Lofoten. In order to maintain a stable population with $\lambda=1$ we increase or decrease the mean offspring length 

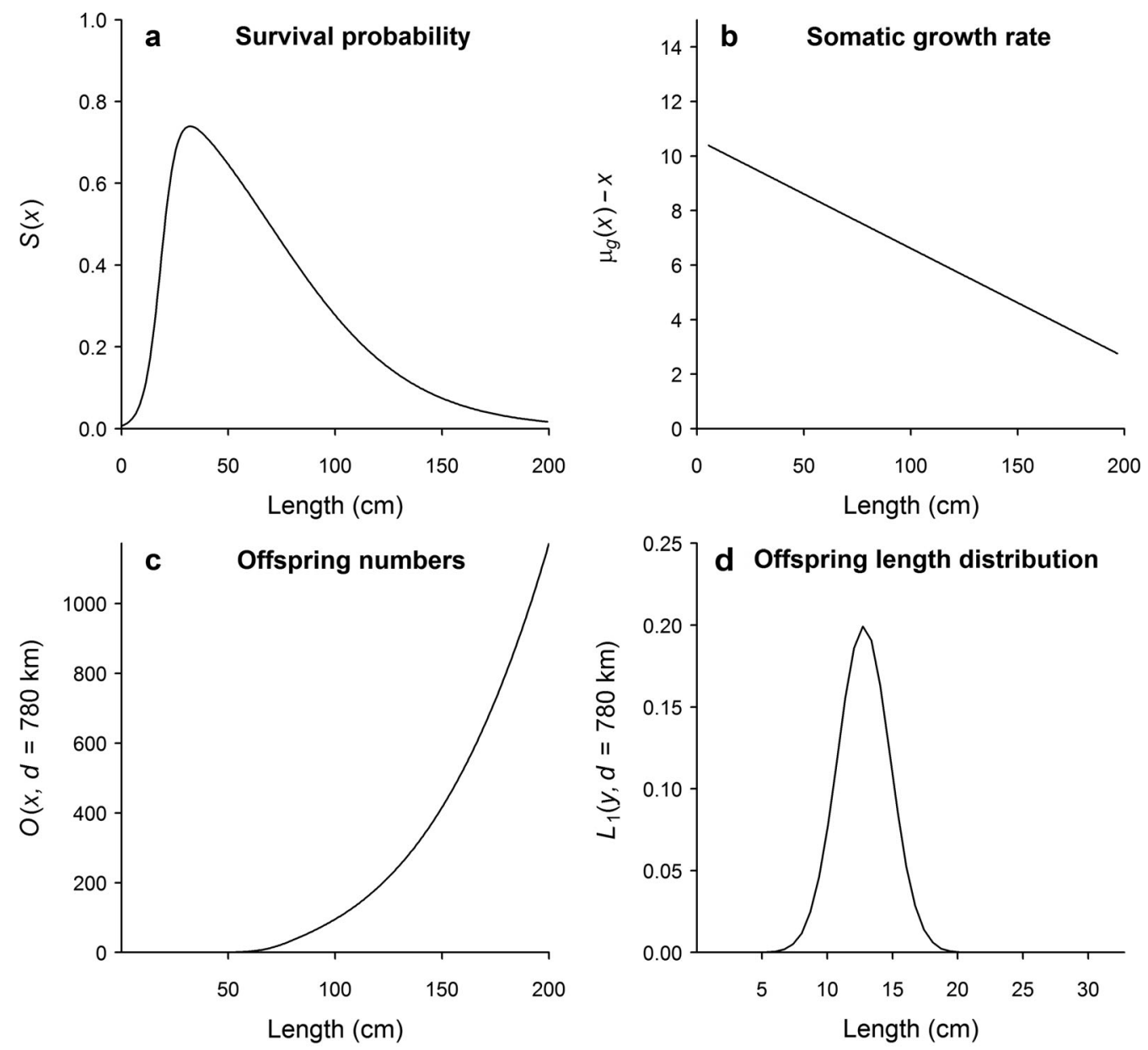

Fig. 2. Vital rate function of the model (parameters in Table S1 in the Supplement). (a) Annual survival probability $S(x)$ depending on current length $x_{i}$ (b) mean annual somatic growth rate $\mu_{g}(x)-x$ (in $\left.\mathrm{cm}\right)$ of fish with current length $x$ after entering the model; (c) offspring function $O(x, d=780 \mathrm{~km})$, i.e. number of 1 yr old offspring produced by a female of length $x ;$ and (d) length distribution of $1 \mathrm{yr}$ old offspring $L_{1}\left(y_{1} d=780 \mathrm{~km}\right)$ when the fish enter the model $(\mathrm{c}, \mathrm{d})$ are shown for the Lofoten baseline model $d=780 \mathrm{~km}$

Next year's length, given current length $x_{1}$ is assumed to follow a normal distribution $G(y ; x)$ with mean $\mu_{\mathrm{g}}(x)$ (visualized as mean growth rate in Fig. 2b), and standard deviation $\sigma=2 \mathrm{~cm}$, calculated based on values by Folkvord et al. (2014) (Table S1). The offspring function $O(x, d)$ describes the number of age- 1 female offspring produced by a mature female of length $x$ (Fig. 2c) and is given by:

$$
O(x, d)=e(x, d) p m(x) S_{\text {first }} 0.5
$$

The offspring function is a main part of our model and consists of the following elements: $(1) e(x, d)$ is the egg number, depending on length $x$ and migration distance $d$. Values for the baseline model set at the Lofoten spawning ground are taken from Marshall et al. (2006), with $e(x, d=780 \mathrm{~km})=e^{-15.09+3.595 \ln (x)}$. This function was used to calculate the egg numbers for various migration distances in combination with energetic calculations (see section below and the Supplement); (2) the length-dependent probability of maturity $p m(x)$ (ICES 2002, 2015, Table S1); and (3) first year survival probability, $s_{\text {first }}=7.2 \times 10^{-5} \mathrm{yr}^{-1}$ (Langangen et al. 2014, Bogstad et al. 2016, see the Supplement) is the survival for the entire first year of life, which was kept constant over all migration distances.

We assumed that the offspring length distribution at age $1, L_{1}(y, d)$, when the fish enter the model, follows a normal distribution with mean length $\mu_{L_{1}}(d=$ $780 \mathrm{~km})=12.79 \mathrm{~cm}($ ICES 2002, 2015) at the Lofoten spawning ground and standard deviation $\sigma_{L_{1}}=2 \mathrm{~cm}$ (Ottersen et al. 2002, Fig. 2d), and is independent of maternal length $x$. Then the fish start growing according to the somatic growth rate (Fig. 2b), described by the length distribution $G(y ; x)$. The growth 
rate during the first year is different and was not explicitly modelled here.

Once the projection kernel $K(y, x, d)$ was defined, we analysed it by discretising the length variable $(d x=0.67)$ to obtain a large projection matrix for each value of $d$ and then applied standard matrix calculations (Caswell 2001). The population's long-term growth rate $\lambda(d)$ (our measure of fitness) is the dominant eigenvalue, while the population's stable size structure $w(x, d)$ is the associated right eigenvector (Ellner et al. 2016).

For our model, we assumed that migration starts in the southern Barents Sea, north of Norway, since the fish aggregate before the spawning migration in their feeding areas in these waters (Yaragina et al. 2011, Johansen et al. 2013). The distance $d$ then ranged from 300 to $1600 \mathrm{~km}$ in the model, corresponding to different spawning locations (e.g. 2 possible spawning grounds are found in Finnmark at around 400 km; Langangen et al. 2016, and Møre at around 1500 km; Jørgensen et al. 2008, Fig. 1). The migrating fish might have a spawning-ground-specific starting point in the Barents Sea (cf. Godø 1984). However, in that case, the actual migration distance is likely shorter for the more distant spawning grounds than the one we used, making our model conservative as it implies a lower increase in offspring length to offset the migration costs than the one actually calculated.

We calculated the energy needs and associated changes in egg numbers $e(x, d)$ relative to the baseline model in Lofoten (see the Supplement). We assumed that all fish have full energy stores, $E_{\max }(x)$, before starting their migration (Tables S2 \& S3). The stored energy and the somatic weight, $W_{\text {soma }}(x)$, influenced the total body mass of the fish and thus the standard metabolic rate SMR $(x)$ (Jørgensen \& Fiksen 2006, Tables S2 \& S3). The metabolic rate and the time needed for the migration, $T_{\mathrm{M}}(d)$, which was influenced by the migration distance, the swimming and current speed for migration south- and northwards (Tables S2 \& S3), determined the total energy needed for the migration, $E_{\mathrm{M}}(X, d)$. The total energy needed, all other costs being equal, in turn influenced the possible egg numbers the fish could produce (Jørgensen \& Fiksen 2006).

Using this model, we first calculated $\lambda(d)$ and stable length structure $w(x, d)$, depending on migration distance $d$ compared to the Lofoten baseline model which is initialized so that $\lambda(d=780 \mathrm{~km})=1$ (Fig. 1). To explore how the reduction in offspring numbers caused by reduction in actual egg numbers $e(x, d)$ due to longer migration distance may be compen- sated by offspring growth, so that $\lambda(d)=1$ for all distances $d$, we adjusted the mean offspring length at age $1, \mu_{L 1}(d)$ while keeping the survival $S(x)$ and length distribution $G(y ; x)$ of fish from age 1 and onwards the same. In other words, a reduction in $\lambda(d>$ $780 \mathrm{~km}$ ) was compensated by an increase of the mean offspring length (i.e. shifting the offspring length distribution $L_{1}(y, d)$ to larger lengths) and vice versa for the shorter migration (Fig. 1). In order to compare the cost and benefits of migration at different spawning grounds, we calculated the normalized relative population's egg numbers $e_{\text {rel }}(d)$ as the integral of the egg number $e(x, d)$ and the normalized stable length structure $w(x, d)$ of mature females for each migration distance respectively, over all possible length ranges:

$$
e_{\text {rel }}(d)=\int_{L}^{U} e(x, d) W(x, d) p m(x) d x
$$

We assumed that this function is zero at each end of the model size range, with the minimum $L=0.01 \mathrm{~cm}$ and the maximum $U=200 \mathrm{~cm}$ (see Fig. 3). With $e_{\text {rel }}(d)$, we show the cost of migration through changes in egg numbers for the population at a specific spawning ground (see Fig. 3c).

Furthermore, we tested the robustness of the model results to changes in the parameters of the vital rate functions. We altered the parameters of, respectively, the survival function (Table S1) and the mean length $\mu_{g}$ of the length distribution $G(y ; x)$ (Table S1) by $\pm 10 \%$. In addition, we also altered the offspring function $O(x, d)$ via the egg numbers $e(x, d=780 \mathrm{~km})$ (Table S1) by $\pm 10 \%$ and reran the model with one change in a parameter at a time.

All calculations were produced with $\mathrm{R}$ version 3.3.2 (R Core Team 2016).

\section{RESULTS}

\section{Migration distance impact on $\lambda$ without compensating effect}

With longer migration distance compared to the main spawning area in the Lofoten area, $\lambda(d)$ predicted from the model decreased (Fig. 3a) due to reduced offspring numbers (resulting from an increase in energy costs that resulted in reduced egg numbers). For example, an increase in migration distance of about $720 \mathrm{~km}$ (corresponding to a spawning in Møre $[d=1500 \mathrm{~km}]$ instead of Lofoten $[d=780 \mathrm{~km}])$ led to a decrease in $\lambda$ by about $4.7 \%, \lambda(d=1500 \mathrm{~km})=0.95$ (Fig. 3a). Conversely, a decrease in migration dis- 

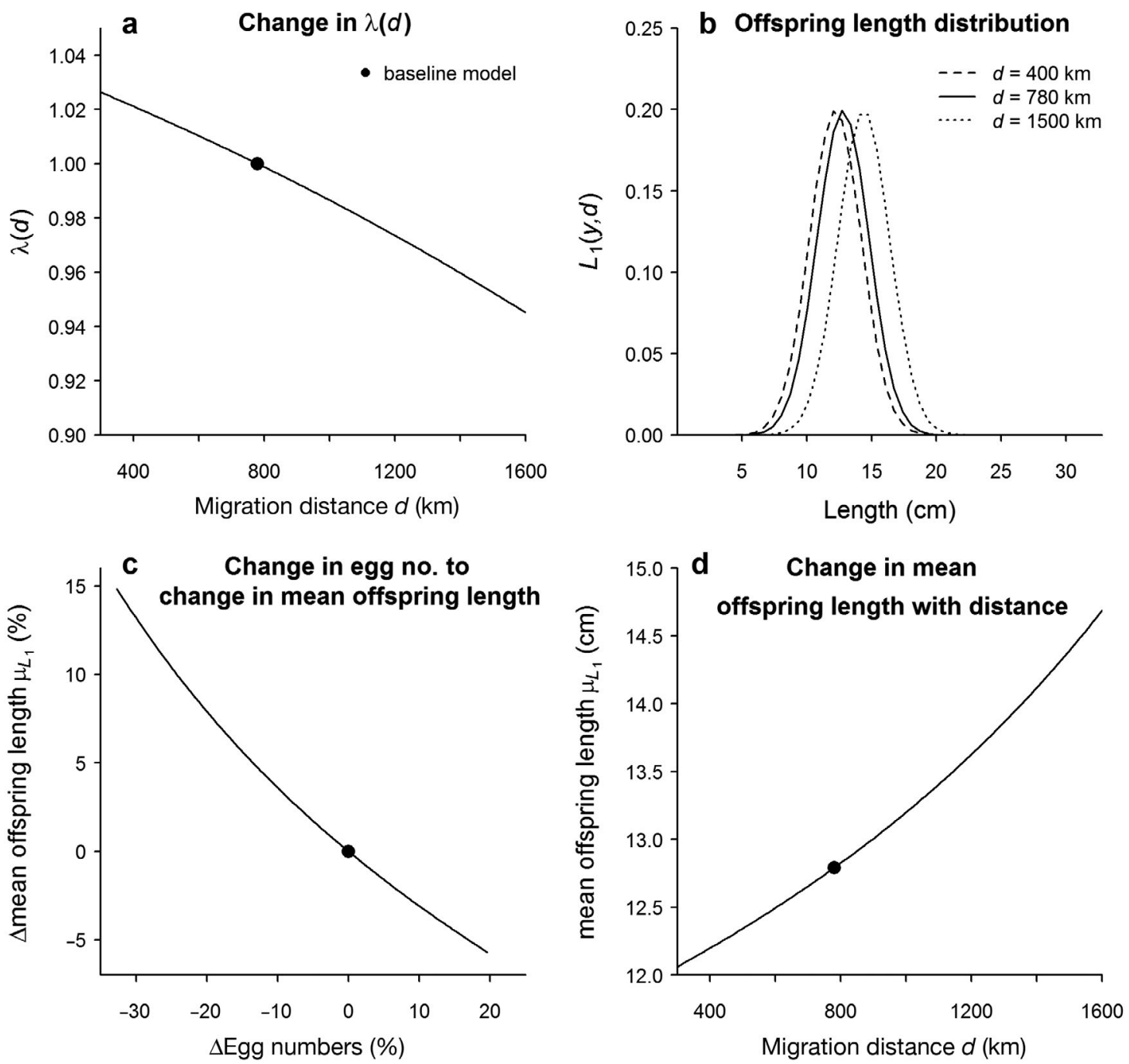

Fig. 3. Model predictions for migration distances from 300 to $1600 \mathrm{~km}$. (a) Change in mean fitness (measured as $\lambda$ ) as a function of distance to the Barents Sea, when not accounting for offsets in offspring length (b) required shift in mean offspring length $\mu_{L_{1}}$ in order to maintain $\lambda=1$ for Finnmark and Møre (400 and $1500 \mathrm{~km}$, respectively); (c) relative change in mean offspring length $\mu_{L_{1}}$ with relative change in the number of eggs; and (d) mean offspring length $\mu_{L_{1}}(\mathrm{~cm})$ as a function of migration distance.

Black dot: results for the Lofoten baseline $d=780 \mathrm{~km}$

tance of around $380 \mathrm{~km}$ (corresponding to a spawning in Finnmark $[d=400 \mathrm{~km}]$ instead of Lofoten) led to an increase in $\lambda$ by about $2.1 \%$, with $\lambda(d=400 \mathrm{~km})$ $=1.02$ (Fig. 3a).

\section{Changes in mean offspring length $\mu_{L_{1}}$ to compensate for the migration effects on $\lambda$}

In order to compensate for the effect on $\lambda(d)$ caused by a shorter or longer migration, i.e. maintain $\lambda(d)=1$ for all migration distances, the offspring length distribution was shifted towards a larger/smaller mean (Figs. $1 \& 3 b$ ) compared to the baseline mean offspring length at the Lofoten spawning ground of
$12.8 \mathrm{~cm}$. At a migration distance of $1500 \mathrm{~km}$ (Møre), the mean offspring length $\mu_{L_{1}}$ should be around $14.4 \mathrm{~cm}$ to counterbalance the parental migration cost (corresponding to a $12.5 \%$ increase). At a distance of $400 \mathrm{~km}$ (Finnmark), this mean can be $12.2 \mathrm{~cm}$ (decrease by $4.6 \%$; Fig. 3b,c). In other words, from the northernmost spawning grounds in Finnmark to the southernmost spawning grounds in Møre the normalized relative egg numbers $e_{\text {rel }}(d)$ decreased by about $44 \%$ (Fig. 3c). However, compensating this decrease in egg numbers would require only about $15 \%$ (around $2 \mathrm{~cm}$ ) increase of the mean offspring length (Fig. 3c,d). When we tested the results for their robustness, model results were most sensitive to changes in the slope $b_{g}$ of the mean 

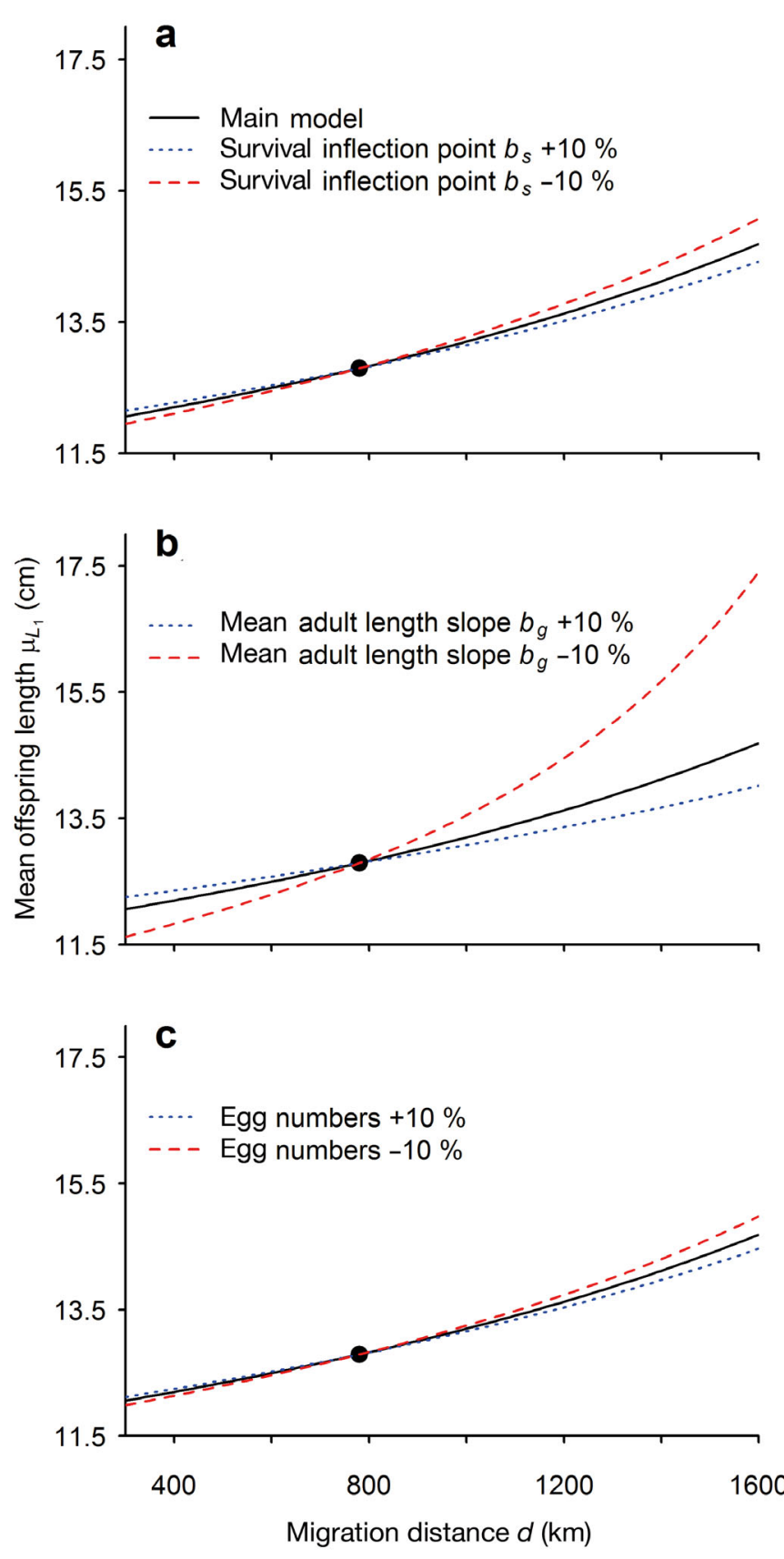

Fig. 4. Changes in mean offspring length, $\mu_{L 1}$, after one-byone alterations of vital rate parameters $(+10 \%$ respective blue lines, $-10 \%$ respective red lines) to test the robustness of results. Only parameters leading to the largest changes are shown; results of the remaining parameters are presented in Fig. S3 in the Supplement. Black line: results from the model without parameter changes; black dot: results for the Lofoten baseline $d=780 \mathrm{~km}$. (a) Maximum changes in mean offspring length caused by changes in survival function through the inflection point $b_{s}$ (Table S1); (b) maximum changes in mean offspring length caused by changes in mean growth function $\mu_{g}$ through the mean growth slope $b_{g}$ (Table S1); (c) changes in mean offspring length through changes in offspring numbers, implemented through changes in egg numbers length $\mu_{g}$ of the next year's growth distribution $G(y ; x)$ (Fig. 4b, see the Supplement). Changes in survival parameters and egg numbers led to only small changes in the results regarding the mean offspring lengths required to meet the parental migration costs (Figs. 4a,c \& S3).

\section{DISCUSSION}

By developing and analysing an IPM accounting for migration distance in addition to length, we demonstrated that relatively small increases in offspring growth during the first year of life are sufficient to offset the parental energy costs of the longdistance spawning migration seen in NEA cod. This result illustrates how the IPM framework can be used to shed light on potential mechanisms behind longdistance migration in species with complex life histories and trade-offs.

Detailed drift models of the early life stages (eggs, larvae, and pelagic juveniles) of NEA cod, combined with empirical estimates of spatial variation in early offspring survival, indicated that an increase in early survival seems unlikely to be the major benefit of long-distance migration in the NEA cod stock (Langangen et al. 2016). Thus, our results suggest a shift in our understanding of this long-distance migration as a parent-offspring trade-off, where parental costs and investments are offset by early offspring survival (Jørgensen et al. 2008, Opdal et al. 2011), to a quality-quantity trade-off in offspring. Here, the increased length of the offspring is the main benefit, which counterbalances the quantitative cost of a reduction in egg numbers. Our model showed that relatively small and biologically realistic changes (cf. Langangen et al. 2016) can alone counterbalance the cost of migrating $1600 \mathrm{~km}$. It would be interesting to test our results of the model empirically to further investigate the hypothesis of offspring growth offsetting parental migration costs.

The survival of early life stages of fish is highly variable due to fluctuations in e.g. predation pressure, food availability, and environmental factors (see Ottersen et al. 2014). Instead, higher survival later in life, which can follow from an increase in length early in life (see Fig. S4 in the Supplement), might have large beneficial effects later in life (cf. Beckerman et al. 2002). It has been shown that this benefit can already be seen at age-1 NEA cod, where larger size for juveniles was suggested to protect against cannibalism (Yaragina et al. 2009). The NEA cod fishery is to a large extent conducted near and 
on the spawning grounds (cf. Hylen et al. 2008, Shevelev et al. 2011). Thus, long-term latitudinal changes in spawning ground distribution due to e.g. climate change (Sundby \& Nakken 2008) may significantly alter the impact of harvesting on population dynamics. These potential impacts on population dynamics are thus highly relevant from a management perspective. Furthermore, our results indicate that the swimming distance might not be a constraining factor for the NEA cod at the population level to reach southern spawning grounds, since only small increases in offspring length would be needed to offset parental costs. The 'choice' of spawning ground may thus be determined by factors other than body reserves alone, especially since the southernmost spawning grounds have been used less since the 1930s (Sundby \& Nakken 2008), despite providing better growth conditions for the offspring (Suthers \& Sundby 1993, Folkvord 2005, Opdal et al. 2011, Langangen et al. 2016). However, to our knowledge there is no empirical evidence that there is indeed a difference in fecundity between the spawners at the different spawning grounds. This would be an interesting topic for further empirical investigations in the future.

\section{Offspring size benefit}

The extra cost of migrating beyond the main spawning ground in Lofoten to the southern spawning ground in Møre can be compensated by an increase in mean offspring length, $\mu_{L_{1}}$ of about $12.5 \%$ (from a mean length in Lofoten of $12.8 \mathrm{~cm}$ to $14.4 \mathrm{~cm}$ in Møre; Fig. 3d). Such a level of increase seems realistic for the NEA cod population since the length is within the range of the observed interannual mean length of age-1 cod, ranging from 10.4 to $17.6 \mathrm{~cm}$ (ICES 2002, 2015). Furthermore, the $5 \%$ length difference of juvenile cod in their first year of life between Lofoten and Finnmark corresponds well to the expected difference estimated using detailed physical-biological drift models for the early pelagic life-stages of NEA cod (Langangen et al. 2016). In the latter, the authors found the juveniles ( $0.5 \mathrm{yr}$ old) to be $20 \%$ bigger in Lofoten than in Finnmark when assuming ad libitum feeding. The results of our robustness analysis also fall within this range (Figs. 4 \& S3). It is important to keep in mind that northern spawned offspring might be able, to some degree, to compensate their early growth disadvantages compared to southern spawned offspring (Jørgensen et al. 2008). This may be possible through the longer light regime in the northern areas compared to southern spawning grounds, which is suggested to be beneficial for visual feeding larvae (Suthers \& Sundby 1996, Jørgensen et al. 2008). Nevertheless, temperature is such an important factor in growth that it likely explains most of the length differences between southern and northern spawned offspring, and this difference is likely retained at their settling points in the Barents Sea (Suthers \& Sundby 1993, Opdal et al. 2011, Ozhigin et al. 2011, Langangen et al. 2016).

\section{Model assumptions}

We assumed for modelling purposes that all the fish start at the same point in the southern Barents Sea on the way to their spawning ground, with the same amount of energy, and that all the energy that is not spent on migration will be spent on egg production regardless of differences between fish (e.g. large and small). This is obviously a simplification; for example, the distribution at the feeding grounds may be dependent on the geographical spawning location in the previous spring (cf. Godø 1984). However, the fish are likely to be congregated in the southern Barents Sea (see e.g. Ciannelli et al. 2007, Johansen et al. 2013) before they start their migration in winter (Ciannelli et al. 2007). Thus, a common starting point seems to be a reasonable approximation for this model. With our model we wanted to explore the average dynamics of a population, hence assuming an equal energy content and usage for reproduction for all fish of a given size is adequate for this purpose. In a future development of the model, we could investigate the consequences of individual differences in these factors as well as other effects of migration on the parents (not only decreased egg numbers), such as increased mortality through e.g. fishing at the spawning sites. Moreover, since individual differences in the size and condition of the spawners might influence their spawning migration (Slotte 1999, Jørgensen et al. 2008), we could develop our model to include individual differences in offspring size and thus broaden the picture drawn by studies focusing on survival as a benefit (Jørgensen et al. 2006, 2008). Our IPM also did not include any density-dependent regulation. For cod, high densities might lead to decreased growth in the unfished size classes of a population (Svedäng \& Hornborg 2014). Furthermore, high density reduces juvenile survival, either through cannibalism (larger cod preying mainly on the age-0 group) or food competition within cohorts (Ohlberger et al. 2014). However, 
our vital rates are based on data from densitydependent models, and thus represent effects at average densities. Our model results on fitness should be interpreted as average long-term patterns, which are relevant to study life history trade-offs. Furthermore, we tested the robustness of the model results by changing the functions of the vital rates; however, the trends of the model remain qualitatively the same (Figs. 4 \& S3).

\section{CONCLUSIONS}

Understanding the trade-offs associated with spawning migration is essential to improve our ability to manage and conserve migratory species under climate change. With global warming, these trade-offs are expected to have implications for, amongst others, the spawning grounds used (Sundby \& Nakken 2008) and the distribution of species (Johannesen et al. 2012, Fossheim et al. 2015). Fisheries and the economies of countries depending on those species will be increasingly affected (Allison et al. 2009). Our study enlarges the picture drawn by previous studies by highlighting the potential importance of offspring growth in explaining the fitness trade-offs associated with long-distance migration in fish. Specifically, we showed that increased early offspring growth alone could be enough to explain the longdistance migration patterns, and that this benefit can lead to long-term population effects. Thus, our results provide guidance to where efforts should be made in the management of human activities at spawning grounds.

Acknowledgements. We thank Nils Christian Stenseth for helpful comments on an earlier draft of the manuscript and 3 anonymous reviewers for further comments that greatly improved the manuscript. L.F. was supported by the MARmaED project. MARmaED has received funding from the European Union's Horizon 2020 research and innovation programme under the Marie Skłodowska-Curie grant agreement No. 675997. The results of this publication reflect only the authors' views and the European Commission is not responsible for any use that may be made of the information it contains. J.M.D. was supported by the Research Council of Norway (RCN) through the project SUSTAIN (244647/E10). Y.V. was supported by a grant from RCN (244404). Ø.L. was supported by the RCN project OILCOM (255487).

\section{LITERATURE CITED}

Alerstam T, Hedenström A, Åkesson S (2003) Long-distance migration: evolution and determinants. Oikos 103:247-260 Allison EH, Perry AL, Badjeck MC, Adger WN and others
(2009) Vulnerability of national economies to the impacts of climate change on fisheries. Fish Fish 10:173-196

Armsworth PR (2002) Recruitment limitation, population regulation, and larval connectivity in reef fish metapopulations. Ecology 83:1092-1104

*Beckerman A, Benton TG, Ranta E, Kaitala V, Lundberg P (2002) Population dynamic consequences of delayed lifehistory effects. Trends Ecol Evol 17:263-269

Block BA, Teo SLH, Walli A, Boustany A and others (2005) Electronic tagging and population structure of Atlantic bluefin tuna. Nature 434:1121-1127

* Bogstad B, Yaragina NA, Nash RD (2016) The early life-history dynamics of northeast Arctic cod: levels of natural mortality and abundance during the first 3 years of life. Can J Fish Aquat Sci 73:246-256

Caswell H (2001) Matrix population models: construction, analysis, and interpretation. Sinauer Associates, Sunderland, MA

Ciannelli L, Dingsør GE, Bogstad B, Ottersen G and others (2007) Spatial anatomy of species survival: effects of predation and climate-driven environmental variability. Ecology 88:635-646

Dingle H (2014) Migration: the biology of life on the move. Oxford University Press, New York, NY

Dodson JJ (1997) Fish migration: an evolutionary perspective. In: Godin JGJ (ed) Behavioral ecology of teleost fishes. Oxford University Press, Oxford, p 10-36

* Durant JM, Hjermann D $\varnothing$ (2017) Age-structure, harvesting and climate effects on population growth of Arcto-boreal fish stocks. Mar Ecol Prog Ser 577:177-188

* Durant JM, Hidalgo M, Rouyer T, Hjermann DØ and others (2013) Population growth across heterogeneous environments: effects of harvesting and age structure. Mar Ecol Prog Ser 480:277-287

* Easterling MR, Ellner SP, Dixon PM (2000) Size-specific sensitivity: applying a new structured population model. Ecology 81:694-708

Ellner SP, Childs DZ, Rees M (2016) Data-driven modelling of structured populations: a practical guide to the integral projection model. Springer International Publishing, Cham

* Folkvord A (2005) Comparison of size-at-age of larval Atlantic cod (Gadus morhua) from different populations based on size- and temperature-dependent growth models. Can J Fish Aquat Sci 62:1037-1052

Folkvord A, Jørgensen C, Korsbrekke K, Nash RDM, Nilsen T, Skjæraasen JE (2014) Trade-offs between growth and reproduction in wild Atlantic cod. Can J Fish Aquat Sci 71:1106-1112

Fossheim M, Primicerio R, Johannesen E, Ingvaldsen RB, Aschan MM, Dolgov AV (2015) Recent warming leads to a rapid borealization of fish communities in the Arctic. Nat Clim Chang 5:673-677

Fournier DA, Hampton J, Sibert JR (1998) MULTIFAN-CL: a length-based, age-structured model for fisheries stock assessment, with application to South Pacific albacore, Thunnus alalunga. Can J Fish Aquat Sci 55:2105-2116

Godø OR (1984) Migration, mingling and homing of northeast Arctic cod from two separated spawning grounds. In: Godø OR, Tilseth S (eds) Reproduction and recruitment of Arctic cod: proceedings of the SovietNorwegian symposium. Institute of Marine Research, Bergen, p 289-302

Harden Jones FR (1968) Fish migration. Edward Arnold, London 
Hylen A, Nakken O, Nedreaas K (2008) Northeast Arctic cod: fishery, life history, stock fluctuations and management. In: Nakken $\mathrm{O}$ (ed) Norwegian spring-spawning herring and northeast Arctic cod: 100 years of research management. Tapir Academic Press, Trondheim, p 83-118

ICES (1994) Spawning and life history information for North Atlantic cod stocks. ICES Cooperative Research Report No. 205. ICES, Copenhagen

ICES (2002) Report of the Arctic Fisheries Working Group (AFWG). ICES CM 2002/ACFM:18

ICES (2015) Report of the Arctic Fisheries Working Group (AFWG). ICES CM 2015/ACOM:05

Johannesen E, Høines ÅS, Dolgov AV, Fossheim M (2012) Demersal fish assemblages and spatial diversity patterns in the Arctic-Atlantic transition zone in the Barents Sea. PLOS ONE 7:e34924

Johansen GO, Johannesen E, Michalsen K, Aglen A, Fotland $\AA$ (2013) Seasonal variation in geographic distribution of North East Arctic (NEA) cod - survey coverage in a warmer Barents Sea. Mar Biol Res 9:908-919

Jørgensen C, Fiksen Ø (2006) State-dependent energy allocation in cod (Gadus morhua). Can J Fish Aquat Sci 63: 186-199

Jørgensen C, Ernande B, Fiksen Ø, Dieckmann U (2006) The logic of skipped spawning in fish. Can J Fish Aquat Sci 63:200-211

Jørgensen C, Dunlop ES, Opdal AF, Fiksen $\varnothing$ (2008) The evolution of spawning migrations: state dependence and fishing-induced changes. Ecology 89:3436-3448

Langangen Ø, Stige LC, Yaragina NA, Vikebø FB, Bogstad B, Gusdal Y (2014) Egg mortality of northeast Arctic cod (Gadus morhua) and haddock (Melanogrammus aeglefinus). ICES J Mar Sci 71:1129-1136

Langangen $\varnothing$, Ottersen G, Ciannelli L, Vikebø FB, Stige LC (2016) Reproductive strategy of a migratory fish stock: implications of spatial variations in natural mortality. Can J Fish Aquat Sci 73:1742-1749

Marshall CT, Needle CL, Thorsen A, Kjesbu OS, Yaragina NA (2006) Systematic bias in estimates of reproductive potential of an Atlantic cod (Gadus morhua) stock: implications for stock recruit theory and management. Can J Fish Aquat Sci 63:980-994

Ohlberger J, Rogers LA, Stenseth NC (2014) Stochasticity and determinism: how density-independent and densitydependent processes affect population variability. PLOS ONE 9:e98940

炎Opdal AF, Vikebø FB, Fiksen $\varnothing$ (2011) Parental migration, climate and thermal exposure of larvae: spawning in southern regions gives Northeast Arctic cod a warm start. Mar Ecol Prog Ser 439:255-262

* Ottersen G, Helle K, Bogstad B (2002) Do abiotic mechanisms determine interannual variability in length-at-age of juvenile Arcto-Norwegian cod? Can J Fish Aquat Sci 59:57-65

* Ottersen G, Bogstad B, Yaragina NA, Stige LC, Vikebø FB, Dalpadado P (2014) A review of early life history dynamics of Barents Sea cod (Gadus morhua). ICES J Mar Sci 71:2064-2087

Editorial responsibility: Stylianos Somarakis, Heraklion, Greece
Ozhigin VK, Ingvaldsen RB, Loeng H, Boitsov VD, Karsakov AL (2011) Introduction to the Barents Sea. In: Jakobsen T, Ozhigin VK (eds) The Barents Sea: ecosystem, resources, management. Half a century of Russian-Norwegian cooperation. Tapir Academic Press, Trondheim, p 39-76

R Core Team (2016) R: a language and environment for statistical computing. R Foundation for Statistical Computing, Vienna

Rankin MA, Burchsted JCA (1992) The cost of migration in insects. Annu Rev Entomol 37:533-559

Robichaud D, Rose GA (2004) Migratory behaviour and range in Atlantic cod: inference from a century of tagging. Fish Fish 5:185-214

Rose GA (2005) Capelin (Mallotus villosus) distribution and climate: a sea 'canary' for marine ecosystem change. ICES J Mar Sci 62:1524-1530

Shevelev MS, Sunnanå K, Gusev EV (2011) Fisheries and hunting in the Barents Sea: history of fisheries and hunting. In: Jakobsen T, Ozhigin VK (eds) The Barents Sea: ecosystem, resources, management. Half a century of Russian-Norwegian cooperation. Tapir Academic Press, Trondheim, p 495-514

Slotte A (1999) Effects of fish length and condition on spawning migration in Norwegian spring spawning herring (Clupea harengus L.). Sarsia 84:111-127

Sundby S, Nakken O (2008) Spatial shifts in spawning habitats of Arcto-Norwegian cod related to multidecadal climate oscillations and climate change. ICES J Mar Sci 65: 953-962

Sutherland WJ (1996) From individual behaviour to population ecology, Vol 11. Oxford University Press, Oxford

* Suthers IM, Sundby S (1993) Dispersal and growth of pelagic juvenile Arcto-Norwegian cod (Gadus morhua), inferred from otolith microstructure and water temperature. ICES J Mar Sci 50:261-270

Suthers IM, Sundby S (1996) Role of the midnight sun: comparative growth of pelagic juvenile cod (Gadus morhua) from the Arcto-Norwegian and a Nova Scotian stock. ICES J Mar Sci 53:827-836

K Svedäng H, Hornborg S (2014) Selective fishing induces density-dependent growth. Nat Commun 5:4152

* Trivers RL (1974) Parent-offspring conflict. Am Zool 14: 249-264

*Vindenes Y, Langangen $\varnothing$ (2015) Individual heterogeneity in life histories and eco-evolutionary dynamics. Ecol Lett 18:417-432

Vindenes Y, Langangen $\varnothing$, Winfield IJ, Vøllestad LA (2016) Fitness consequences of early life conditions and maternal size effects in a freshwater top predator. J Anim Ecol 85:692-704

Yaragina NA, Bogstad B, Kovalev YA (2009) Variability in cannibalism in northeast Arctic cod (Gadus morhua) during the period 1947-2006. Mar Biol Res 5:75-85

Yaragina NA, Aglen A, Sokolov KM (2011) Cod. In: Jakobsen T, Ozhigin VK (eds) The Barents Sea: ecosystem, resources, management. Half a century of RussianNorwegian cooperation. Tapir Academic Press, Trondheim, p 225-270

Submitted: November 10, 2017; Accepted: June 7, 2018 Proofs received from author(s): July 19, 2018 